\title{
Local benefits factored in utility scale wind energy for a remote location
}

\author{
Mohamed Hassan Soliman, Bassel I. Nesser \\ VSB-Technical University of Ostrava, Czech Republic \\ Krzysztof Pytel \\ AGH University of Science and Technology, Poland
}

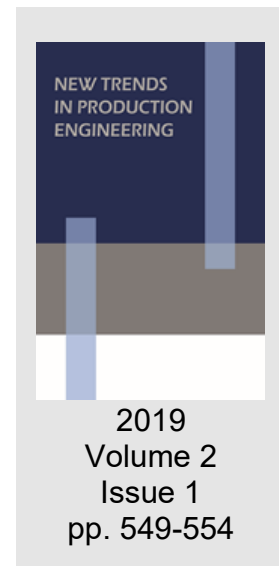

Date of submission to the Editor: 05/2019

Date of acceptance by the Editor: 08/2019

\section{INTRODUCTION}

The growing demand for energy production forces the need to find an alternative source of energy generation in a more efficient form. People have used wind energy for sailing, pumping water and grinding grain since ancient times. The next stage could be the use of wind to generate electricity, but it was not used due to the invention of the steam engine. For more than two hundred years since the use of a steam engine, wind energy has been used to generate mechanical energy. It was not until the second half of the $20^{\text {th }}$ century that wind energy became an important sector of renewable energy that can be defined. Now, wind energy production, as a pure form of energy production, is considered one of the fastest growing sectors of renewable energy production methods. Wind energy production eliminates the use of coal, oil, gases and even water. Thus, this type of energy generation systems works with zero greenhouse gas emissions (Burton, 2011).

All methods of generating energy affect the environment in a specific way, even methods of generating renewable energy. This is because some sectors of renewable energy production can damage the environment through greenhouse gases. Wind energy involves the use of structures and huge areas, and common disadvantages include wild life disturbances, flickering and high noise levels (Letcher, 2017).

Wind energy has become one of the most needed and desirable power to control, produce and manage, it has become one of the simplest and effective energy to produce. The wind energy technology became essential in the green energy production especially in most of the world.

Generally, two forms of wind devices exist: the most commonly used the horizontal axis wind turbine (HAWT) and vertical axis wind turbine (VAWT) (Gumula, 2015). 


\section{METHODOLOGY OF RESEARCH}

In this publication, a genuine system of renewable island consisted of the wind energy is being designed. The renewable energy ventures are considered to be practicable to achieve great success in generating efficient and reliable energy for specific areas and islands. There are examples of islands that have become renewable energy autonomous. An island can be defined as the small spaces of land surrounded by water from every point. Most of the islands are mainly depended on fossil fuel power plants that generate the necessary energy share. Main objectives of this paper is to show and present example of wind farm for generating electricity in order to make the island independent of energy from external energy sources. An additional goal of the work is to show the fully rely on renewable energy sources, that is advantages of deploying of wind turbines on island. The renewable energy projects on a remote island can show the impact on the island environment by reducing greenhouse gas emissions. The technological effect is a progressive approach to generate energy from renewable sources, especially from wind energy. The financial result is a reduction in energy prices paid by the island's inhabitants (Gipe, 2016).

The purpose of the work is to select the elements of the energy system. The climatic conditions have been studied and the maximum wind speeds that can affect the strength of structures for wind power plants have been determined. The second step of the analysis was to verify the obtained power and to estimate the project costs. The impact on the environment is an exceedingly important section of the investment. Based on the obtained information, guidelines for further analysis were developed.

\section{RESULTS OF RESEARCH}

Various aspects affect the project in wind energy. Some features need to be assessed in relation to the selection of a remote location in order to achieve effective energy production from a wind farm. The objective of design part is analysis of climatic conditions and selection of appropriate components of the power production system. The characteristics of technical factors affect the selection process and the environmental aspect, which concerned the process of analyzing the climate of the proposed region and the assessment of the most important properties that specifies the wind farm's energy production.

There are several factors to consider when choosing the perfect place for the wind farm. One of the most important criteria when choosing a location are wind resources, availability of the location for the power plant, topography, environmental impact of devices, grid connection. Wind speed is the most important factor in the energy production process from wind energy. This accessibility can be classified based on the annual wind speed in the selected location. Wind speeds of no less than $7 \mathrm{~m} / \mathrm{s}$ are considered to be perfect for onshore wind turbines, whereas wind speeds above $13 \mathrm{~m} / \mathrm{s}$ are essential for offshore wind turbines. Another factor is the environmental impact of the wind farm. Because wind turbines occupy an open space interacting with 
communities, the environmental impact is represented by visual impact, related regional wild life and noise level (Walker and Swift, 2015).

Essentially, the decision of choosing the proposed location for a project is based on climate analysis, location selection policy, technical factors of site selection and environmental aspects. The leading factor in the erection of a wind farm is primarily the regional climate (Fig. 1) and energy demand (Fig. 2) in selected location.

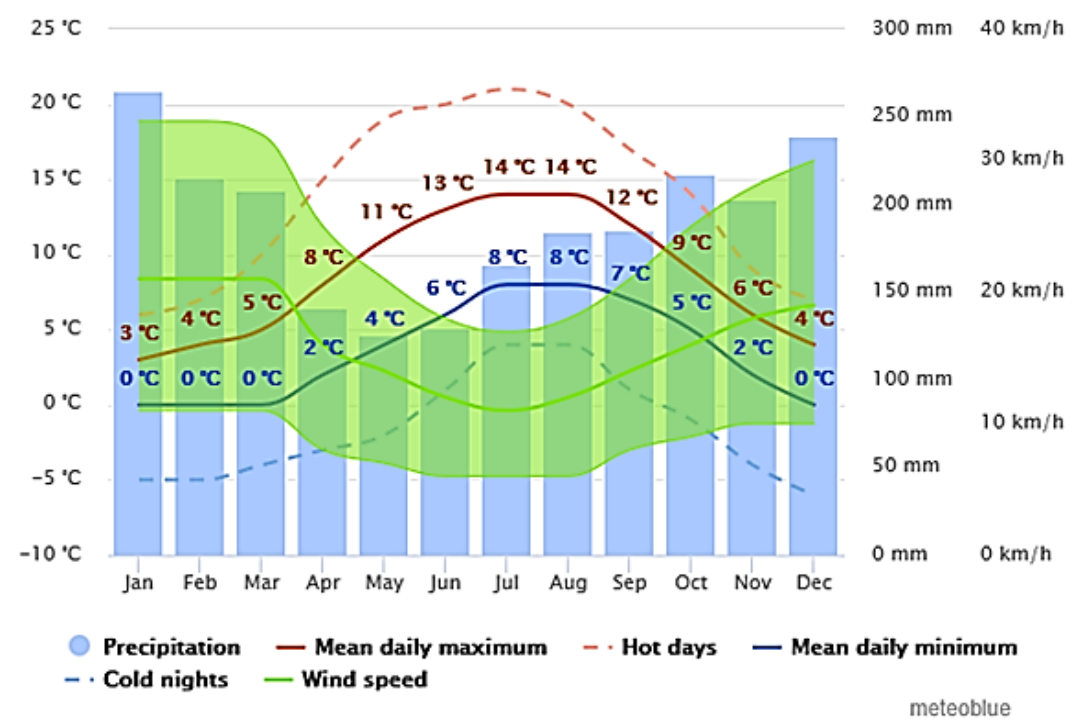

Fig. 1 Visual information about climate condition in selected location

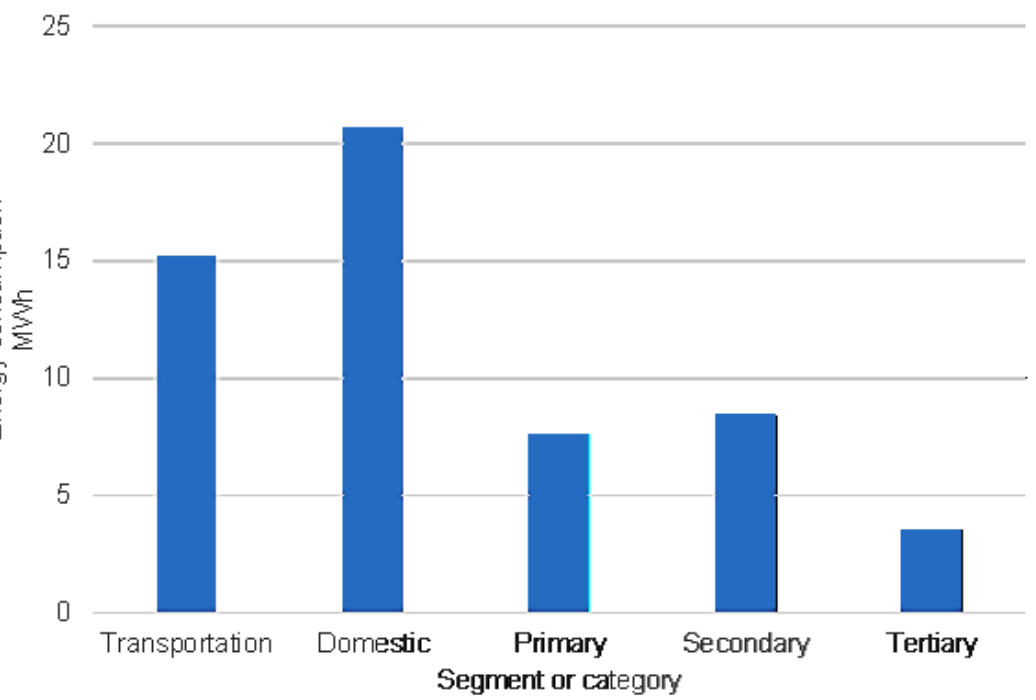

Fig. 2 Visual information about total energy consumption in selected location

The important factor of the designated location is the wind speed (Fig. 3). The availability of the wind along the year is clear and the wind speeds is in the operational range of produced wind (meteoblue corporation, 2019).

All of these factors are carefully evaluated and studied.

The total energy consumption can be divided into segments. There are transport and domestic segments as well as three main economic segments describing the supply chain of finished products and services. 


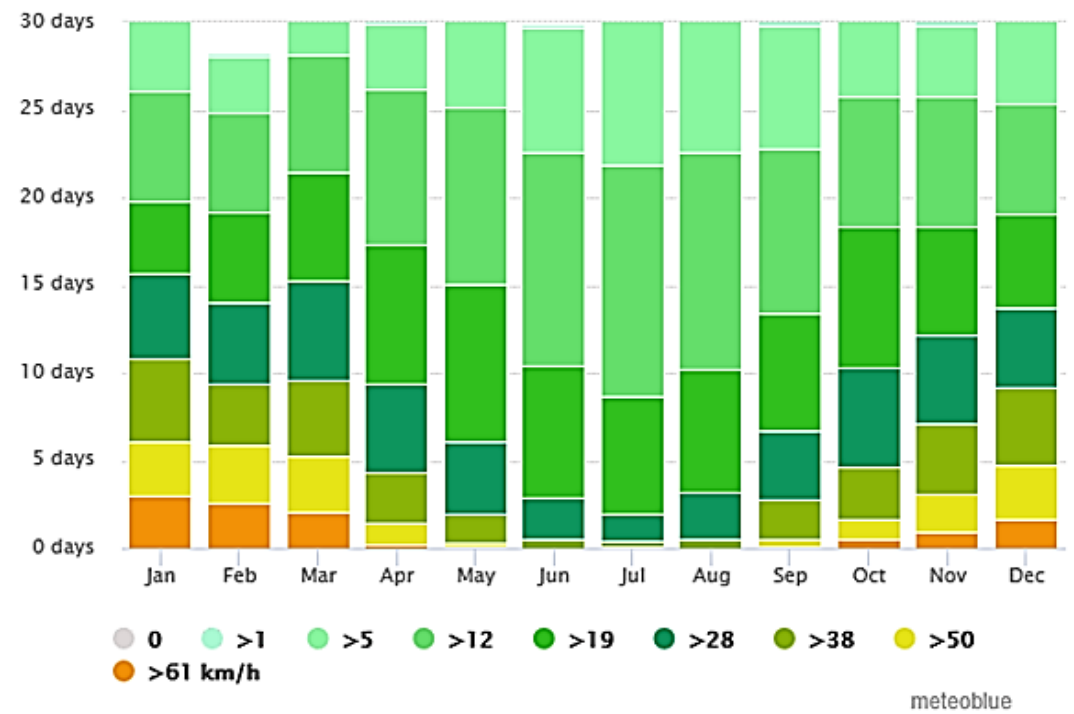

Fig. 3 Visual information about wind speed in selected location

The raw material extraction routes define the primary segment. The secondary segment is related to the transformation of raw materials into finished products and related to construction and development. The tertiary segment is related to the final procedure of delivering the final product or service to the consumer (Price, 2014).

The most important and analyzed segments of electricity consumption, up to $90 \%$, are domestic and tertiary. The total energy consumption within this sectors (24.184 MWh/y), converted to megawatts, is equal to $11.04 \mathrm{MW}$, and this is the amount of energy needed to generate by the wind turbines. The amount of energy produced by the wind turbine depends on air density, wind speed, type of turbine. Mainly two leading parameters are the air density and the wind speed (Gumula, 2015).

The cold air helps in creating a denser airflow with a higher density. The cold and dense airflow increases the power generated by the wind turbine, but eliminates the turbulent flow with higher speeds from creating the phenomena of flow separation and thus decreases the power generated. Wind speed is the most important parameter in the power generation equation, because this factor is cubed which means that any slight increase or decrease in the wind speed influence on the wind turbines power output (Sanz, M.G. and Houpis, 2012).

Wind turbine selection was based on calculations of amount of power required to be obtained and operating wind speed of each proposed wind turbine (Table 1).

Table 1 Designated wind turbines description

\begin{tabular}{|c|c|c|c|c|c|}
\hline $\begin{array}{c}\text { Wind } \\
\text { turbine }\end{array}$ & $\begin{array}{c}\text { Operating wind } \\
\text { speed, } \mathbf{~ m / s}\end{array}$ & $\begin{array}{c}\text { Turbine } \\
\text { capacity, } \mathbf{M W}\end{array}$ & $\begin{array}{c}\text { Blade length } \\
\mathbf{r}, \mathbf{~ m}\end{array}$ & $\begin{array}{c}\text { Turbine swept } \\
\text { area A, } \mathbf{~ m}^{\mathbf{2}}\end{array}$ & $\begin{array}{c}\text { Total number } \\
\text { of turbines }\end{array}$ \\
\hline WT1 & $11-14$ & 1.5 & 38.5 & 4656.62 & 15 \\
\hline WT2 & $11.2-13.5$ & 2 & 46.25 & 6720.06 & 10 \\
\hline WT3 & $10.3-12.5$ & 2.5 & 54.5 & 9331.31 & 8 \\
\hline
\end{tabular}

Based on the results of analysis of designated wind turbines calculation, the most preferred turbine is the WT3 with the power of $2.5 \mathrm{MW}$. This is related to 
the low number of units required to produce the needed amount of power, potentially the smallest area occupied by the wind farm and the lowest investment, operation and maintenance costs, as well.

It can be distinguish taking into account EWEA reports, that according LCA in wind energy, the environment impact of wind energy production is diminutive. Carbon dioxide emissions maximum value equals to $9.6 \mathrm{~g} / \mathrm{kWh}$, methane emissions maximum value equals to $15.4 \mathrm{mg} / \mathrm{kWh}$, nitrogen oxides emissions maximum value equals to $38.6 \mathrm{mg} / \mathrm{kWh}$, non-methane volatile organic compounds maximum value equals to $8.5 \mathrm{mg} / \mathrm{kWh}$, sulphur dioxide emissions maximum value equals to $41.4 \mathrm{mg} / \mathrm{kWh}$, and particulates maximum value equals to $32.3 \mathrm{mg} / \mathrm{kWh}$. Contribution of the different life cycle phases to the relevant emissions (Fthenakis and Alsema, 2006). Comparing individual wind turbine LCA phases: construction, operation and dismantling, it can be noticed that generally about $80 \%$ of all pollutants come from the construction phase.

\section{CONCLUSION}

The main aim of this paper was to investigate the ability of erecting a wind farm to generate power for a remote location by an onshore wind turbines. The selection process of the location was carried out carefully while taking into consideration the factors related to obtaining the maximum power generation out of the deployed wind turbines.

The selected location energy and electrical consumption was evaluated, to form an opinion about the needed amount of energy required to be provided to the locals of that specified zone. The fact of generating energy from a clean, cheap and reliable source, such as wind energy, has been taken into account. Data regarding the regional climate specifications as wind velocities, air temperature and precipitation levels was showed for a long time period of time exceeding twenty years of recorded data, the main purpose of this was to introduce a realistic picture about establishing such a project in selected remote location. A wind turbine was chosen and it was estimated that the environment impact of chosen wind turbine, including their number, is diminutive.

\section{REFERENCES}

Burton, T. (2011). Wind Energy Handbook. John Wiley and Sons Ltd.

Letcher, T.M. (2017). Wind Energy Engineering. Elsevier Science Publishing Co Inc.

Gipe, P. (2016). Wind Energy for the Rest of Us: A Comprehensive Guide to Wind Power and How to Use It. wind-works.org.

Gumula, S. Hudy, W. Piaskowska-Silarska, M. and Pytel, K. (2015). The effect of greenhouse gases and natural factors on the changes in Earth temperature. Przemysł Chemiczny, 94 (9), pp. 1515-1517.

Fthenakis, V. and Alsema, E. (2006), Photovoltaics energy payback times, greenhouse gas emissions and external costs: 2004-early 2005 status, Progress in Photovoltaics, 14, pp. 275-280.

Walker, R.P. and Swift, A. (2015). Wind Energy Essentials: Societal, Economic, and Environmental Impacts 1st Edition. Wiley.

meteoblue corporation. (2019). Available at: https://www.meteoblue.com/en/weather/historyclimate/climatemodelled/isle-ofmull_united-kingdom_7290043 [Accessed 11 May, 2019]. 
Price, G.D. (2014). Power Systems and Renewable Energy: Design, Operation, and Systems Analysis (Power Generation Collection). Momentum Press.

Sanz, M.G. and Houpis, C.H. (2012). Wind Energy Systems. Control Engineering Design. CRC Press.

\begin{abstract}
.
The publication presents the results of analysis of possible local benefits factored in utility scale wind energy for a remote location. Electricity is one of the most vital problems on the Earth, thus utility scale wind and solar energy devices are boosting economic development. Energy demand is constantly increasing, despite efforts to ensure the energy efficiency of devices. People are looking for more energy and electricity to consume. Although wind energy is still being researched and improved, modern generation of wind energy is becoming more and more effective and desirable. This publication presents an effective solution to this issue. It deals with the generation of green environment friendly electricity from wind turbine. The genuine idea is to provide energy for remote location using onshore wind turbines. An analysis of the demand for energy at a remote location and electricity consumption was made to provide preliminary calculations of the wind farm. The number of required turbines is determined taking into account all related factors. A specific wind turbine has been selected and proposed to provide the necessary location with the necessary amount of energy. The analysis carried out showed that the produced energy is environment friendly since there is no carbon dioxide emission.
\end{abstract}

Keywords: Horizontal Axis Wind Turbine, Energy Generation, Greenhouse Gases 